\section{ORIGINAL PAPER}

doi: 10.5455/medarh.2018.72.116-119

MED ARCH. 2018 APR; 72(2): 116-119

RECEIVED: JAN 20, 2018 | ACCEPTED MAR 15, 2018

${ }^{1}$ Clinic for Anaesthesiology and Reanimatology, University Clinical Center Tuzla, Tuzla, Bosnia and Herzegovina

2Department of Clinical Pharmacology, University Clinical Center Tuzla, Tuzla, Bosnia and Herzegovina

${ }^{3}$ Center for Palliative care, University Clinical Center Tuzla, Tuzla, Bosnia and Herzegovina

Corresponding author: Jasmina Smajic, Clinic for Anaesthesiology and Reanimatology, University Clinical Center Tuzla, Tuzla, Bosnia and Herzegovina. ORCID ID: https://orcid. org: 0000-0003-1635-5490. Telephone number: 0038761721353 ; Fax number: 0038735303125, E-mail: jasnasnamjic@gmail. com.

(c) 2018 Jasmina Smajic, Lejla Rakovac Tupkovic, Samir Husic, Selma Sijercic Avdagic, Samir Hodzic, Semir Imamovic

This is an Open Access article distributed under the terms of the Creative Commons Attribution NonCommercial License (http://creativecommons.org/ licenses/by-nc/4.0/) which permits unrestricted non-commercial use, distribution, and reproduction in any medium, provided the original work is properly cited.

\title{
Systemic Inflammatory Response Syndrome in Surgical Patients
}

\author{
Jasmina Smajic ${ }^{1}$, Lejla Rakovac Tupkovic ${ }^{2}$, Samir Husic ${ }^{3}$, Selma Sijercic \\ Avdagic $^{1}$, Samir Hodzic ${ }^{1}$, Semir Imamovic ${ }^{1}$
}

\begin{abstract}
Objective: To determine the incidence of systemic inflammatory response of the organism in surgical patients and its impact on the outcome of treatment. Methods: A prospective study was conducted on 60 patients undergoing abdominal surgical procedures, between January 2014 and December 2015 in the Surgery Clinic at the University Clinical Center Tuzla. Two groups of thirty were formed by the method of consecutive sampling. The first group consisted of subjects who were prepared for elective abdominal surgery (laparoscopic cholecystectomy), and the second group subjects underwent an emergency surgery due to acute abdomen (laparoscopic cholecystectomy). Results: The body temperature difference was statistically significant between the two investigated groups in all stages $\left(c^{2}: t_{0}=3,486 ; t_{1}=3,098\right.$; $t_{2}=2,453, t: t_{0}=-11,210 ; t_{1}=-7,360 ; t_{2}=-4,927, p<0,05$ ). Non-elective surgery group had a statistical significant difference of the heart rate at all stages $\left(c^{2}: t_{0}=3,873 ; t_{1}=3,357 ; t_{2}=3,227\right.$, $\left.t: t_{0}=-16,524 ; t_{1}=-10,407 ; t_{2}=-9,842, p<0,05\right)$. There is a statistically significant difference in the pCO2 values in all stages between groups $\left(c^{2}: t_{0}=2,582 ; t_{1}=1,678 ; t_{2}=1,162, t: t_{0}=4,323\right.$; $t_{1}=2,653 ; t_{2}=2,229, p<0,05$ ). The SIRS score has a good positive correlation with the length of treatment, while the correlation with the outcome of treatment has no statistical significance. Conclusion: Inflammation scores monitoring in surgical patients is important for the surgical treatment success analysis. By modifying the therapy and influencing the inflammatory response, the results of treatment are improved.
\end{abstract}

Keywords: systemic inflammatory response syndrome, inflammation, acute phase reaction.

\section{INTRODUCTION}

Stress is a set of noxious agents that adversely affect the body: trauma, shock, surgery, pain. The body's response to stress depends on the strength of the stressor and the body condition before the action of the stress agent. With better body condition the response to a stressful state is more turbulent (1). The stress response of a body implies hormonal and metabolic changes after injury or trauma. The systemic response to the surgical trauma implies the activation of the sympathetic nervous system, the endocrine response to stress, immunological and hematological changes (2). Inflammation is an expected, usually localized response of the body, followed by systemic signs of varying intensity, induced by tissue damage or destruction. Main goal of inflammation is to destroy, alleviate or eliminate provoking factors or to limit the size of the tissue damage, and to start the tissue repair $(3,4)$. If the inflammatory reaction of the body is not localized, it is affecting the whole body, within the systemic inflammatory response of the organism. Systemic inflammatory response of the organism is the reflection of action of the acute phase reaction mediators. SIRS is a non-specific reaction caused by an acute insult in the body, which leads to the defense reaction of the body, with the goal to localize and eliminate endogenous or exogenous insult. Inflammatory cascade is a complex process that includes humoral and cellular responses, complement, and cytokines $(5,6)$. Objective of the study was to determine the incidence of systemic inflammatory response of the organism in surgical patients and its impact to the outcome of treatment.

\section{MATERIALS AND METHODS}

A prospective study was conducted on 60 patients undergoing abdominal surgical procedures, between January 2014 and December 2015 in the Surgery Clinic at the University Clinical Center Tuzla. Two groups of thirty were formed by the method of consecutive sampling. The first group (elective) consisted of subjects who were prepared for abdominal 
elective surgery (laparoscopic cholecystectomy), and the second group (non-elective) subjects underwent an emergency surgery due to acute abdomen (laparoscopic cholecystectomy). The subjects of both groups belonged both sexes, age from 18-70, and were the I-IV group of anesthesiology risk according to the classification of the American Association of Anesthesiologists (ASA). Patients were operated under general anesthesia. They all signed informed consent. Preoperatively we recorded data regarding name, gender, age, co-morbidity and parameters including body temperature, heart rate, pCO2, number of leukocytes, which represent the initial value of the test parameters ( $\mathrm{t} 0$ ). The same parameters were analyzed 24 and 72 hours after the surgical procedure, which represents the value of $t 1$ and $t 2$. We valuated the intensity of the inflammatory response of the body based on these SIRS score parameters: a) Body temperature higher than $38^{\circ} \mathrm{C}$ or lower than $36^{\circ} \mathrm{C}$; b) Heart rate greater than 90 beats per minute; c) Respiratory frequency greater than 20 breaths per minute or $\mathrm{pCO} 2$ less than $4.3 \mathrm{kPa}$; ) The number of leukocytes greater than 12,000 or less than 4,000 , or the presence of more than $10 \%$ of immature neutrophils. Each positive parameter was given with one point. Two or more points indicate the systemic inflammatory response of the body. Statistical tests were done using the SPSS 19.0 software package. Variables were tested for normality with a Kolmogorov-Smirnov test. Standard methods of descriptive statistics were used: mean and standard deviation, t-test and $X^{2}$ test for calculating the significant difference between the expected frequencies and the observed frequencies. The relationships between variables were tested using both Pearson and Spearman's correlation.

\section{RESULTS}

The study included two groups of 30 subjects aged 18 to 70 years. In the elective surgery group (Group 1), the average age was $47.53 \pm 15.44$, while the average age in the non-elective surgery group (Group 2) was $56.03 \pm$ 20.10 years. In Group 1, the majority of subjects were 51-65 years of age, and in Group 2 they were 66-80 years old. Of the 60 analyzed patients, 26 were male and 34 were female. The majority of subjects were without co morbidities. In the elective surgery group subjects were hospitalized for $3.40 \pm 1$ days hospitalization, while in the non-elective surgery group subjects were hospitalized for $8.70 \pm 5.88$ days $(\mathrm{p}<0.05)$. All patients from the elective surgery group were discharged home, while 25 non-elective surgery group subjects were discharged while elderly 5 subjects died $(\mathrm{p}=0.023)$. The body temperature difference was statistically significant between the two investigated groups in all stages $\left(\mathbf{c}^{2}: \mathrm{t}_{0}=3,486\right.$; $\mathrm{t}_{1}=3,098 ; \mathrm{t}_{2}=2,453, \mathrm{t}: \mathrm{t}_{0}=-11,210 ; \mathrm{t}_{1}=-7,360 ; \mathrm{t}_{2}=-4,927, \mathbf{p}$ $<0,05)$. Wilcoxon's paired t-test showed that there was a statistically significant difference in body temperature at all stages in non-elective surgery group subjects, while in the elective surgery group, this difference only exists between Stage t0 and t1. Non-elective surgery group subjects had a statistical significant difference of the heart rate at all stages $\left(\mathbf{c}^{2}: \mathrm{t}_{0}=3,873 ; \mathrm{t}_{1}=3,357 ; \mathrm{t}_{2}=3,227, \mathrm{t}\right.$ : $\mathrm{t}_{0}=-$

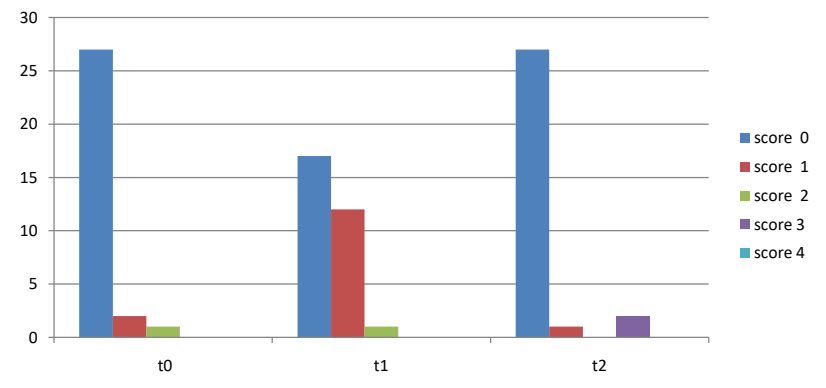

Figure 1. SIRS score of the elective surgery group subjects

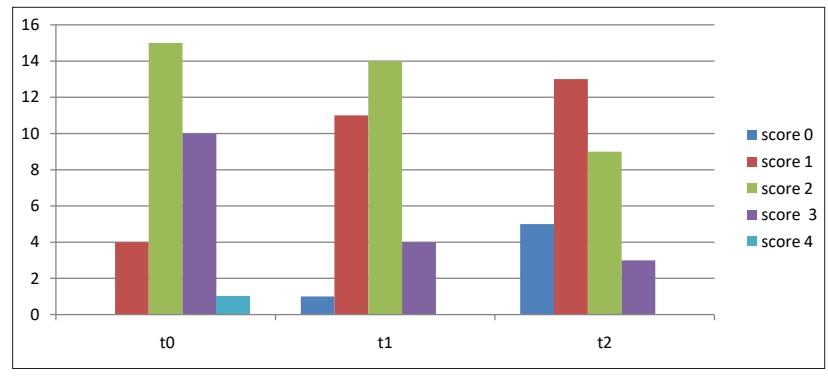

Figure 2. SIRS score of the non-elective surgery group subjects

\begin{tabular}{lcc}
\hline \multirow{2}{*}{ Variable } & \multicolumn{2}{c}{ Hospital stay days } \\
\cline { 2 - 3 } & Correlation coefficient & Correlation significance \\
\hline SIRS_score_t0 & .553 & .000 \\
\hline SIRS_score_t1 & .522 & .000 \\
\hline SIRS_score_t2 & .436 & .001
\end{tabular}

Table 1. Correlation of duration of the hospital stay days with SIRS score

\begin{tabular}{lcc}
\hline \multirow{2}{*}{ Variable } & \multicolumn{2}{c}{ Treatment outcome } \\
\cline { 2 - 3 } & Correlation coefficient & Correlation significance \\
\hline SIRS_score_t0 & -.247 & .057 \\
\hline SIRS_score_t1 & -.240 & .065 \\
\hline SIRS_score_t2 & -.250 & .054 \\
\hline
\end{tabular}

Table 2. Correlation of the treatment outcome with SIRS score

16,$\left.524 ; t_{1}=-10,407 ; t_{2}=-9,842, \mathbf{p}<0,05\right)$. There is a statistically significant difference in the $\mathrm{pCO} 2$ values in all stages between groups $\left(\mathbf{c}^{2}: t_{0}=2,582 ; t_{1}=1,678 ; t_{2}=1,162\right.$, $t$ : $\left.t_{0}=4,323 ; t_{1}=2,653 ; t_{2}=2,229, p<0,05\right)$. Analyzing the differences between value of the parameters during stages (t0, $\mathrm{t} 1$, and $\mathrm{t} 2$ ), Wilcoxon paired $\mathrm{t}$-test showed that there was statistically significant difference in the number of leukocytes in all stages for both groups of subjects. The largest leukocytes count for the elective surgery group was in $t_{1}$, and in the non-elective surgery group in $t_{0}$. Statistically significant difference in the number of leukocytes between groups was in $t_{0}(p<0001)$. An analysis of the parameters that represent the extent of the body's inflammatory response has shown that systemic inflammatory response occurs after both elective and non-elective surgery, but with a statistically significant difference in its incidence. Elective surgery group had a low incidence of systemic inflammatory response of the body (Figure 1), as opposed to a non-elective surgery group, with high incidence ( $<0.0001$ ) (Figure 2).

The SIRS score has a good positive correlation with the length of treatment, while the correlation with the out- 
come of treatment has no statistical significance (Table 1 and 2).

\section{DISCUSSION}

The acute phase reaction of the body is a complex series of reactions that begin in response to infection, physical trauma or malignancy, and is characterized by leukocytosis, elevated body temperature, changes in the metabolism of many organs, and the change in the concentration of various acute phase proteins in plasma (7).

Early systemic leukocytosis appears due to surgical stress. The increased release of cortisol as the body's response to stress or administration of adrenaline during major surgical procedures also affects the increase in the number of leukocytes $(8,9)$. Hong (10) published the results of a study that analyzed changes in the number of leukocytes in patients who underwent laparoscopic surgery due to endometriosis comparing preoperatively administration of ketorolac vs placebo. Preoperative ketorolac reduced postoperative pain and influenced the WBC response. In our study, the non-elective surgery group subjects had an increase in the leukocytes count in $t_{0}$, while in the elective surgery group subjects this increase is seen in $t_{1}$. In the non-elective surgery group there is a gradual decline in the leukocytes count in $t_{1}$, but it is still above the upper limit, with the tendency of decreasing in $t_{2}$, when it is within the reference range. In $t_{1}$ for the elective surgery group, the increased number of leukocytes is lower than the increased number of leukocytes for the non-elective surgery group, but without a statistically significant difference, with the tendency further decreasing to 2 when it is at the reference range and lower than in subjects from non-elective surgery group. Therefore, in non-elective surgery group inflammatory reaction caused by the condition for which the surgical procedure is indicated, leads to an increase in the number of leukocytes, which gradually decreases during recovery time, because the root cause is eliminated, and it has been cleared up with an operative procedure. Changes of the leukocytes count were proportional to the changes of the neutrophils count. Numerous studies have shown that elevated body temperature is a frequent sign of the first and second postoperative day in large operative procedures, mostly caused by an inflammatory stimulus of surgery $(11,12,13)$. Wortel et al. (14) reported that the postoperative level of IL- 6 is directly proportional to the value body temperature. Other studies have shown that the risk of postoperative temperature is greater with a larger operative procedure (15). In our study, in elective surgery group there was no increase in body temperature at any stage of the examination. Non-elective surgery group had an elevated temperature at all stages, and the highest in $\mathrm{t}_{0}$ with a downward trend after elimination of the cause of inflammation by surgery. The value of the body temperature of our subjects is well correlated with the leukocyte count.

In our study, elective surgery group had a lower heart rate than non-elective surgery group. Elective surgery group subjects came prepared for surgery. The stress stimulus that triggers the response of the organism is only a surgical procedure, and due to the activation of the sympathetic nervous system, there is a significant difference in heart rate in $t_{1}$. However, non-elective surgery group subjects were hospitalized due to acute abdomen and that had already triggered the stress response, and they had tachycardia in $t_{0}$. The operative procedure is the cause of stress to body, but also removes the stimulus that has already triggered the inflammatory reaction in the non-elective surgery group subjects; therefore we had lower values of the heart rate in $t_{1}$ and $t_{2}$. Saha and associates (16) published the results of a study that analyzed hemodynamic changes in subjects undergoing surgery of the upper abdomen. They reported that preoperative administration of low dose propranolol stabilizes hemodynamic changes caused by surgical trauma.

Activation of the sympathetic nervous system during the stress response of the body and the emergence of the so-called hyper adrenergic condition do not only causes hemodynamic changes-hypertension and tachycardia, but also causes the hyperventilation. Tachypnea may be a reflection of increased metabolic stress during inflammation or infection, but may also be a threatening sign of inadequate perfusion that results in anaerobic cell metabolism (17). The cause of tachypnea in the inflammatory response of the organism depends on the intensity and duration of action of the stress agent, as well as the activation and ability of the compensatory mechanisms of the organism to neutralize the action of the stress stimulus. If the stress stimulus is low to moderate intensity, with shorter action and with compensatory mechanisms sufficient to neutralize the effect of the stress stimulus, then tachypnea is mainly a reflection of the so-called hyper adrenergic condition. With more potent long acting stress agent, due to poor perfusion of the peripheral tissues, anaerobic metabolism starts to produce acid products with a stimulating effect on the respiratory center. In our study, elective surgery group subjects were not in hypocapnia at any stage of the study, as opposed to non-elective surgery group subjects in whom the lowest value of $\mathrm{pCO} 2$ was recorded in $\mathrm{t}_{0}$ with the gradual increase in $t_{1}$ and $t_{2}$. Hypocapnia in this group of subjects may be a reflection of a hyper adrenergic condition but also a sign of weaker perfusion, since the surgery eliminate the primary cause of the inflammatory cascade, hydration improves perfusion, PCO2 values increases, but are still under reference range. Surgical procedure induces the onset of an inflammatory cascade and the release of inflammatory cytokines. Laparoscopic surgery reduces both local and systemic production of cytokines and acute-phase reactants, and preserves better the peritoneal immune ability compared to open surgical procedures (18). If it persists the action of the stress stimulus from damaged tissue with addiction of action of another stress stimulus, the local response transforms into the systemic reaction of the organism known as the systemic inflammatory response of the organism (19). SIRS is a serious condition characterized by systemic inflammation leading to organic dysfunction, sometimes several organ systems. It is a form of cytokine storm, with an abnormal regulation of different cytokines. Criteria confirming the 
systemic reaction of the organism to the action of stress stimulus were established in 1992 at the Conference of the American College of Thoracic Doctors and the Association of Intensive Medicine and since then have been used in clinical practice. Takenaka and associates (20) published the results of study showing that postoperative monitoring of the parameters of the acute phase (IL-6 and CRP) and the parameters of SIRS is very significant, because they correlate well with the intensity of surgical stress and length of hospitalization. The Hague et al. (21) investigated the appearance of SIRS and multiorgan dysfunction in patients who underwent gastrointestinal surgery. The results showed that the length of the SIRS or the number of positive SIRS criteria after surgery significantly correlated with the parameters of surgical stress (blood/weight loss, duration of operation) and CRP value. The SIRS that continued or reappeared after the third postoperative day was an early sign of postoperative complications. They concluded that SIRS is a useful criterion for recognizing postoperative complications and organic dysfunction. Becher et al. (22) published the results of a study, in wich they investigate the effect of an inflammatory response on the outcome of treatment for patients undergoing emergency surgery in the colorectal area. They concluded that the impossibility of regulating the systemic inflammatory response of the organism was the primary cause of the death of non-elective surgery group subjects, and patients with SIRS or sepsis in whom the surgical procedure lasted less than 2.5 hours had less postoperative complications. Their results further reinforce the concept of the importance of surgical intervention in the right time with the best possible control of tissue manipulation, which potentially reduces inflammation. In our study, significantly more incidence of SIRS score had non-elective surgery group subjects, preoperatively $(86.7 \%)$, with a tendency of gradual decrease in the next stages of the study (60\% in $\mathrm{t}_{1}$ and $40 \%$ in $t_{2}$ ). The preoperatively high incidence of SIRS score is a result of the already launched inflammatory reaction. The postoperative incidence is still high and gradually decreases as the root cause of the inflammatory response is resolved, but its residual effects are interpose with the effect of the performed surgery procedure, as a stress stimulus. Positive SIRS criteria are a postoperative reflection of a triggered inflammatory cascade, but with a tendency to settle. The SIRS score of our subjects correlates well with the duration of hospitalization, and somewhat weaker with the outcome of treatment. A weaker correlation with the outcome of treatment is explained by settling the inflammatory cascade within 72 hours. It is likely that we would have a better correlation, if the SIRS parameters were monitored after this period.

\section{CONCLUSION}

The surgical procedure triggers the inflammatory reaction of the organism, which is manifested by the change of the parameters of the inflammation. Elective surgery procedures are characterized by a localized inflammatory reaction, whereas patients, who are operated due to an acute surgical condition, have a high incidence of sys- temic inflammatory response to the organism. Monitoring inflammation scores in surgical patients is important for analyzing of the success of surgical treatment. By modifying the therapy and influencing to the inflammatory response, the results of treatment are improved.

- Conflict of interest: none declared.

- Author contribution J.S. made substantial contribution to conception and design, acquisition of data, analysis and interpretation of data, drafted the article, critically revised the article for important intellectual content and approved final version to be published. L.R.T. made substantial contribution to analysis and interpretation of data. S.H. drafted the article. S.S.A. and S.H. made substantial contribution to acquisition of data.

\section{REFERENCES}

1. Kaluđerović M. Metabolički odgovor organizma na stres. U: Lalević $\mathrm{P}$ (urednik): Anesteziologija. IV izdanje. Beograd, Zavod za udžbenike i nastavna sredstva, 1999; 182-96.

2. Desborough J. The stress response to trauma and surgery. Br J Anaesth 2000; 85(1): 109-17.

3. Weissman G. Inflammation: Historical perspectives. In: Gallin JJ, Goldstein IM, Snyderman E, editors. Inflammation: Basic Principles and Clinical Correlates, 2nd ed. New York: Raven Press, 1992.

4. Warren JS, Ward PA. The Inflammatory Response. In: Lichtman MA, Beutler E, Kipps TJ, Seligsohn U, Kaushansky K, Prchal JT, editors. Williams Hematology, 7' ed. New York:McGraw-Hill, 2006.

5. Nystrom PO. The systemic inflammatory response syndrome: definitions and aetiology. J Antimicrob Chemother. 1998; 41(suppl 1): 1-7.

6. Bone RC, Balk RA, Cerra FB. Definitions for sepsis and organ failure and guidelines for the use of innovative therapies in sepsis. The ACCP/SCCM Consensus Conference Committee. American College of Chest Physicians/ Society of Critical Care Medicine. Chest. 1992; 101: 1644-55.

7. Foex BA. Systemic response to trauma. Br Med Bull. 1999; 76: 352-4.

8. Street S J, Plank L D, Hill GL. Overview of modern management of patients with critical injury or severe sepsis. World J Surg. 2000; 24: 673-80.

9. Fung YL, Fraser JF, Wood P, Minchinton RM, Silliman CC. The systemic inflammatory response syndrome induces functional changes and relative hyporesponsiveness in neutrophils. J Crit Care. 2008; 23(4): 542-9.

10. Hong JY. The Effect of Preoperative Ketorolac on WBC Response and Pain in Laparoscopic Surgery for Endometriosis. Yonsei Med J. 2005; 46(6): 812-7.

11. Galicier C, Richet H. A prospective study of postoperative fever in a general surgery department. Infect Control. 1985; 6: 487.

12. Pile JC. Evaluating postoperative fever: a focused approach. Cleve Clin J Med. 2006; 73(Suppl 1): S62-66.

13. Burke L. Postoperative fever: a normal inflammatory response or cause for concern. J Am Acad Nurse Pract. 2010; ;22(4): 192-7.

14. Wortel CH, van Deventer SJ, Aarden LA, Lygidakis NJ, Büller HR, Hoek FJ, Horikx J, Cate JW. Interleukin-6 mediates host defense responses induced by abdominal surgery. Surgery. 1993; Sep;114(3): 564-70.

15. Frank SM, Kluger MJ, Kunkel SL. Elevated thermostatic setpoint in postoperative patients. Anesthesiology. 2000; 93: 1426-31.

16. Saha DK, Kader A, Kamal M, Akhtaruzzaman AKM, Iqbal KM. Effect of Low Dose Propranonol on Perioperative Stress Induced Hemodynamic Changes in Upper Abdominal Surgery. Journal of BSA. 2006; 19(1): 14-9.

17. Goldstein B, Giroir B, Randolph A. International pediatric sepsis consensus conference: definitions for sepsis and organ dysfunction in pediatrics. Pediatr Crit Care Med. 2005; 6(1): 2-8.

18. Sido B, Teklote JR, Hartel M, Friess H, Büchler MW. Inflammatory response after abdominal surgery. Best Pract Res Clin Anaesthesiol. 2004; 18(3):439-54.

19. Udelsman R, Holbrook NJ. Endocrine and molecular responses to surgical stress. Curr Probl Surg. 1994; 31: 653-728.

20. Takenaka K, Ogawa E, Wada H, Hirata T. Systemic inflammatory response syndrome and surgical stress in thoracic surgery. J Crit Care. 2006; 21(1): 48-53.

21. Haga Y, Beppu T, Doi K, Nozawa F, Mugita N, Ikei S, Systemic inflammatory response syndrome and organ dysfunction following gastrointestinal surgery. Crit Care Med. 1997; Dec; 25(12): 1994-2000.

22. Becher RD, Hoth JJ, Miller PR, Meredith JW, Chang MC. Systemic inflammation worsens outcomes in emergency surgical patients. J Trauma Acute Care Surg. 2012; 72(5): 1140-9. 